\title{
Endogenous Thrombin Potential Lag Time Measurement
}

National Cancer Institute

\section{Source}

National Cancer Institute. Endogenous Thrombin Potential Lag Time Measurement. NCI

Thesaurus. Code C102264.

A measurement of time from the start of the thrombin generation test to the point where a predetermined amount of thrombin is generated. 